\title{
Colorectal cancer screening program using FIT: quality of colonoscopy varies according to hospital type
}

\section{다 (용}

\section{Authors}

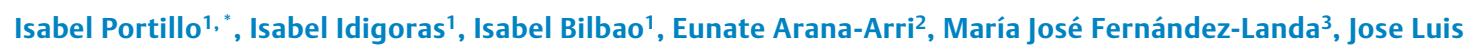
Hurtado ${ }^{4}$, Cristina Sarasaqueta ${ }^{5}$, Luis Bujanda ${ }^{6,}$, for the EUSKOLON study investigators

\section{Institutions}

1 Colorectal Cancer Screening Programme Coordination Center, Bilbao, Spain

2 BioCruces Health Research Institute, Barakaldo, Spain

3 Basurto-Bilbao Health Organization, Osakidetza-Basque Health Service, Bilbao, Spain

4 Araba Health Organization, Osakidetza-Basque Health Service, Vitoria, Spain

5 Hospital Universitario Donostia/Instituto Biodonostia, Red de Investigación en Servicios de Salud en Enfermedades Crónicas (REDISSEC), San Sebastián, Spain

6 Gastroenterology Department, Instituto Biodonostia, University of Basque Country (UPV/EHU), Centro de Investigación Biomédica en Red de Enfermedades Hepaticas y Digestivas (CIBERehd), San Sebastián, Spain

submitted 22.11.2017

accepted after revision 5.6.2018

Bibliography

DOI https://doi.org/10.1055/a-0655-1987 |

Endoscopy International Open 2018; 06: E1149-E1156

(c) Georg Thieme Verlag KG Stuttgart · New York

ISSN 2364-3722

Corresponding author

Luis Bujanda, Avda Sancho El Sabio 17-2Dcha, 20010 San

Sebastián, Spain

Fax: +34-943-007065

medik@telefonica.net

\section{ABSTRACT}

Background and study aims To compare the quality of colonoscopy in a population-based coordinated program of colorectal cancer screening according to type of hospital (academic or non-academic).

Patients and methods Consecutive patients undergoing colonoscopy after positive FIT ( $\geq 20 \mathrm{ug} \mathrm{Hb} / \mathrm{g}$ feces) between January 2009 and September 2016 were prospectively included at five academic and seven non-academic public hospitals. Screening colonoscopy quality indicators considered were adenoma detection rate, cecal intubation rate, complications and bowel preparation quality.

Results A total of 48,759 patients underwent colonoscopy, $34,616(80 \%)$ in academic hospitals and 14,143 in non-academic hospitals. Among these cases, 19,942 (37.1\%) advanced adenomas and 2,607 (5.3\%) colorectal cancers (CRCs) were detected, representing a total of 22,549 (46.2\%) cases of advanced neoplasia. The adenoma detection rate was $64 \%, 63.1 \%$ in academic hospitals and $66.4 \%$ in non-academic hospitals $(P<0.001)$. Rates of advanced adenoma detection, cecal intubation and adequate colonic preparation were $45.8 \%, 96.2 \%$ and $88.3 \%$, respectively, and in all cases were lower (implying worse quality care) in academic hospitals ( $45.3 \%$ vs $48.7 \%$; odds ratio [OR] 0.87 , $95 \%$ confidence interval [Cl] $0.84-0.91 ; 95.9 \%$ vs $97 \%$; OR $0.48,95 \% \mathrm{Cl} 0.38-0.69$; and $86.4 \%$ vs $93 \%$; OR $0.48,95 \%$ Cl $0.45-0.5$; respectively; $P<0.001$ in all cases). In 13 patients, all in the academic hospital group, CRC was diagnosed after colonoscopy ( 0.26 cases $\times 1000$ colonoscopies). Rates of CRC treated by endoscopy were similar in both types of hospital (30\%). The rate of severe complication was $1.2 \%$ (602 patients), with no significant differences by hospital type: bleeding occurred in $1 / 147$ colonoscopies and perforation in $1 / 329$. One patient died within 30 days after screening colonoscopy.

Conclusions The quality of colonoscopy was better in nonacademic hospitals. The rate of detection of advanced neoplasia was higher in non-academic hospitals and correlated with the rate of post-colonoscopy CRC.

\footnotetext{
* These authors contributed equally.
} 


\section{Introduction}

Cancer is the leading cause of death in Western countries. Colorectal cancer (CRC) has the highest incidence (both sexes) and is the second leading cause of cancer death after lung cancer $[1,2]$. Colon cancer screening programs aim to reduce mortality by detecting advanced adenomas or colon cancer at an early stage (I or II).

Colonoscopy is one of the key tools in any CRC screening strategy. It allows visualization of the entire colon, detection and removal of adenomas, and diagnosis and treatment of CRC. The adenoma detection rate (ADR) has become the most important indicator of the quality of colonoscopy because it is directly related to key outcome indicators, such as interval cancer rates [3]. To ensure adequate quality, screening colonoscopies should comply with established minimum quality standards [4]. In particular, good or excellent bowel cleansing is essential, poor cleansing being known to increase risk of complications, such as bleeding and perforation.

An academic or university hospital is a medical center that provides clinical education and training to physician residents in various specialties (e. g., gastroenterology) and other health professionals under a supervising (attending) physician. In general, these centers are considered tertiary hospitals.

Most studies analyzing the quality of colonoscopy are based on data from academic hospitals or tertiary hospitals. It is therefore very important to know whether the quality of colonoscopy in a population screening program is the same in different types of hospitals. In this context, the purpose of this study was to determine the quality of colonoscopies and detection of lesions in a screening program using fecal immunochemical testing by hospital type.

\section{Patients and methods}

\section{Study population and interventions}

An observational nested study was conducted to investigate factors related to quality of colonoscopy in a screening program. The colorectal cancer screening program in the Basque Country (Spain) was developed and progressively rolled out from 2009 to 2014, reaching a coverage of $96 \%$ of the target population (an estimated 586,700 people) $[5,6]$. Individuals aged 50 to 69 were offered a biennial fecal immunochemical test (FIT). FITs (OC-Sensor) were considered positive if samples contained $\geq 20 \mu \mathrm{g} \mathrm{Hb} / \mathrm{g}$ feces.

We included all colonoscopies performed in the screening program after a positive FIT between January 2009 and September 2016. During that period, 1,377,398 patients accepted invitations for FIT tests and 56,548 obtained positive results. Among these cases, 52,241 patients underwent colonoscopy (92.3\% compliance rate). All colonoscopies were included in our analysis, except those performed in private clinics $(n=$ 3,482 ), because of difficulties monitoring some quality parameters and complications.

The 13 public hospitals that conducted the colonoscopies analyzed were classified as academic or non-academic. All the academic hospitals were referral centers for advanced endos- copy (echoendoscopy, endoscopic retrograde cholangiopancreatography, etc.) that provide training to physician residents in gastroenterology and are affiliated with a medical school or university. In general, these hospitals have more than 300 beds and serve a population of over 100,000. Other hospitals were defined as non-academic. Overall, seven of the participating hospitals were classified as non-academic and six as academic.

Colonoscopies were performed under sedation and almost always by experienced specialists who conduct at least 300 colonoscopies per year. On some occasions, in the academic hospitals, trainees perform the colonoscopies supervised by staff doctors (with the aforementioned level of experience). In the event of polyps being found, a staff doctor should take over, confirming type and size of lesions and as appropriate removing them. All patients were followed-up with close coordination between primary care and specialized units. Each case was coded by the coordinating office staff following standard European Union guidelines and Spanish Network consensus recommendations [7,8].

For all colonoscopies across the hospitals participating in the study, magnesium citrate with sodium picosulfate (Citrafleet) was used for bowel preparation, splitting the dose between the day before and the day of colonoscopy. Further, in all hospitals, sedation was achieved with propofol by an anesthetist or endoscopist. Colonoscopies were all performed using standard white light video equipment and none using prescheduled panchromoendoscopy.

Histology of all lesions detected was evaluated by experienced pathologists specialized in gastrointestinal oncology in accordance with quality standards set out in the European guidelines [9]. The following were recorded: the furthest point reached in the colonoscopy, adequacy of bowel preparation, and characteristics and location of any polyps. Adenomas $\geq 10$ $\mathrm{mm}$, with a villous component (i.e., tubule-villous or villous adenoma) and/or with severe/high-grade dysplasia were classified as advanced adenomas (AAs) [9], and other adenomas as non-advanced or low-risk adenomas (LRAs). Advanced neoplasia (AN) was defined as CRC plus AA. Tumors were staged according to the TNM classification system published in the American Joint Committee on Cancer Staging Manual [10]. Finally, participants were classified and then assigned to treatment according to the most advanced lesion found. Stage I or II cancer was considered early-stage disease. The proximal colon was considered to include the cecum, ascending colon, or transverse colon. Individuals were classified as having proximal adenomas if any adenomas were located in the proximal colon and distal adenomas if adenomas were found only in the distal colon.

For identification of interval cancers, detected prior to the next scheduled screening appointment, we developed an evaluation process in which screening registries and cancer registries were linked, including data on causes of death [11-13]. Interval post-colonoscopy colorectal cancer was defined as CRC diagnosed after a screening or surveillance exam in which no cancer was detected and before the date of the next recommended exam [11]. 
- Table 1 General characteristics of colonoscopies by hospital type.

\begin{tabular}{|c|c|c|c|c|c|}
\hline & $\begin{array}{l}\text { Total } \\
\mathrm{N}\end{array}$ & $\begin{array}{l}\text { Academic hospitals } \\
\mathrm{N}\end{array}$ & $\begin{array}{l}\text { Non-academic hospitals } \\
\mathrm{N}\end{array}$ & $\begin{array}{l}\text { Odds ratio } \\
\text { (95\% Cl) }\end{array}$ & $P$ value \\
\hline & 48,759 & 34,616 & 14,143 & & \\
\hline Sex (males) & 29,109 (59.7\%) & $20,596(59.5 \%)$ & $8,500(60 \%)$ & $0.98(0.94-1.02)$ & 0.2 \\
\hline \multicolumn{6}{|l|}{ Aged, years } \\
\hline $49-54$ & $10,971(22.5 \%)$ & $7,789(22.5 \%)$ & $3,406(22.4 \%)$ & ref & \\
\hline $55-59$ & $11,507(23.6 \%)$ & $8,204(23.7)$ & $3,558(23.4 \%)$ & $1.00(0.95-1.07)$ & 0.3 \\
\hline $60-64$ & $12,755(26.2 \%)$ & $9,104(26.3 \%)$ & $3,953(26 \%)$ & $1.00(0.95-1.06)$ & 0.25 \\
\hline $65-69$ & $13,409(27.5 \%)$ & $9,519(27.5 \%)$ & $4,303(28.3 \%)$ & $0.97(0.92-1.02)$ & 0.23 \\
\hline Cecal intubation & $46,906(96.2 \%)$ & 33,187 (95.9\%) & 13,719 (97\%) & $0.48(0.38-0.69)$ & $<0.001$ \\
\hline $\begin{array}{l}\text { Colonic preparation } \\
\text { (adequate) }\end{array}$ & $43,054(88.3 \%)$ & $29,901(86.4 \%)$ & $13,153(93 \%)$ & $0.48(0.45-0.51)$ & $<0.001$ \\
\hline Low risk adenoma & $8,670(17.8 \%)$ & $6,160(17.8 \%)$ & $2,510(17.7 \%)$ & $1.00(0.95-1.06)$ & 0.9 \\
\hline Advanced adenoma & $19,942(40.9 \%)$ & 13,767 (39.8\%) & $6,175(43.7 \%)$ & $0.85(0.82-0.89)$ & $<0.001$ \\
\hline Colorectal cancer & $2,607(5.3 \%)$ & $1,900(5.5 \%)$ & 707 (5\%) & $1,10(1.01-1.21)$ & 0.03 \\
\hline Advanced neoplasia & $22,549(46.2 \%)$ & $15,667(45.3 \%)$ & $6,882(48.7 \%)$ & $0.87(0.84-0.91)$ & $<0.001$ \\
\hline Complication & $602(1.2 \%)$ & $431(1.2 \%)$ & $171(1.2 \%)$ & $1.03(0.86-1.23)$ & 0.7 \\
\hline
\end{tabular}

Bowel cleansing was classified following the Boston Bowel Preparation Scale (BBPS) to evaluate adequacy of preparation $[14,15]$. With that scale, each segment of the colon is graded from 0 to 3, depending on how well the colon mucosa can be seen and an aggregate score is obtained by summing the scores for all three segments, yielding a score between 0 and 9 . In this study, total BBPS scores $>6$ were considered to indicate successful bowel preparation.

Cecal intubation was defined as insertion of the endoscope tip to a point proximal to the ileocecal valve such that the entire cecal pole, including the medial wall (located between the ileocecal valve and appendiceal orifice), is visualized and explored. Colonoscopies that did not reach the cecum were considered inconclusive or incomplete.

All cases were followed and linked with hospital discharges and emergency care to detect any severe or minor complications within 30 days. Bleeding, perforation, and other conditions were considered severe complications if they required the patient to remain in hospital after the procedure for at least 24 hours or, in patients discharged after of colonoscopy, required readmission within 30 days after the procedure. These other conditions included postpolypectomy syndrome (abdominal pain without perforation or microperforation) and respiratory or heart failure related to sedation. Hypotension, arrhythmias, or transient hypoxemia were considered mild complications. Other data collected were: history of abdominal surgery, anticoagulant or antiplatelet use, number of polyps resected, existence of diverticula, and body mass index.

This study was approved by the local ethics committee. All participants provided written informed consent.

\section{Data analysis}

Categorical variables were described using frequencies and percentages and continuous variables using means and standard deviations and/or medians and interquartile ranges depending on characteristics of the data distribution. Categorical variables were compared with the chi-square test or Fisher's exact test. Multivariate logistic regression was used to estimate risk of injury during screening by hospital type. A $P$ value less than 0.05 was considered to indicate statistical significance. Finally, 95\% confidence intervals (Cls) were calculated in all cases. All the statistical analysis was performed with IBM SPSS, Statistics for Windows, Version 22.0 and STATA 13.

\section{Results}

During the study period, 48,759 individuals underwent colonoscopy in participating hospitals, 34,616 in academic hospitals and 14,143 in non-academic hospitals ( $>$ Table 1 ). A total of $31,693,13,653$ and 3,413 colonoscopies were performed in first, second and third screening rounds, respectively. The cecal intubation rate recorded was $96.2 \%$, significantly higher in nonacademic hospitals than academic hospitals (97\% vs $95.9 \%$; odds ratio $[\mathrm{OR}] 1.52,95 \%$ confidence interval $[\mathrm{Cl}] 1.38-1.69$; $P<0.001)$ and also significantly higher in men than women (96.4\%, 95\% Cl 96.4-96.7, vs 95.8\%, 95\% Cl 95.7-96; $P<$ $0.001)$. Rates of adequate colonic preparation were $88.3 \%$ (95\% Cl 87.9-88.5), being lower in academic hospitals $(86.4 \%$ vs $93 \%$; OR $0.48,95 \% \mathrm{Cl} 0.45-0.51 ; P<0.001)$, but unlike the cecal intubation rate, higher in women than men $(89.4 \%, 95 \%$ $\mathrm{Cl} 89-89.9$, vs $87.6 \%, 95 \% \mathrm{Cl} 87.2-88.1 ; P<0.001)$. 
- Table 2 Stage of cancer and treatment by hospital type.

\begin{tabular}{|c|c|c|c|c|c|c|c|c|c|c|c|}
\hline & & & & \multicolumn{2}{|c|}{$\begin{array}{l}\text { Academic hospitals } \\
1,900\end{array}$} & \multicolumn{3}{|c|}{$\begin{array}{l}\text { Non-academic Hospitals } \\
707\end{array}$} & \multicolumn{2}{|c|}{$\begin{array}{l}\text { Odds ratio } \\
(95 \% \mathrm{Cl})\end{array}$} & $P$ value \\
\hline \multicolumn{12}{|c|}{ Colorectal cancer stage } \\
\hline \multicolumn{4}{|l|}{ । } & \multicolumn{2}{|c|}{$1,006(52.9 \%)$} & \multicolumn{3}{|c|}{$373(52.7 \%)$} & \multicolumn{2}{|l|}{ ref } & \\
\hline \multicolumn{4}{|l|}{$\|$} & \multicolumn{2}{|c|}{$324(17.1 \%)$} & \multicolumn{3}{|c|}{$113(16.0 \%)$} & \multicolumn{2}{|c|}{$1.06(0.83-1.36)$} & 0.6 \\
\hline \multicolumn{4}{|l|}{ III } & \multicolumn{2}{|c|}{$443(23.3 \%)$} & \multicolumn{3}{|c|}{$156(22.1 \%)$} & \multicolumn{2}{|c|}{$1.05(0.85-1.31)$} & 0.6 \\
\hline \multicolumn{4}{|l|}{ IV } & \multicolumn{2}{|c|}{$117(6.2 \%)$} & \multicolumn{3}{|c|}{$51(7.3 \%)$} & \multicolumn{2}{|c|}{$0.85(0.60-1.20)$} & 0.4 \\
\hline \multicolumn{4}{|l|}{ Unknown } & \multicolumn{2}{|c|}{$10(0.5 \%)$} & \multicolumn{3}{|c|}{$14(2 \%)$} & \multicolumn{2}{|c|}{$0.27(0.12-0.60)$} & $<0.001$ \\
\hline \multicolumn{4}{|c|}{ Post-colonoscopy cancer (interval cancer) } & $13(0$. & 5 cases $(1000)$ & & cases/1000) & & $5.24(0.6$ & $-39.92)$ & 0.1 \\
\hline Treatmen & & & & & & & & & & & \\
\hline Endoscop & & & & $575(30$ & & 210 & $.2 \%)$ & & ref & & 0.4 \\
\hline Surgical & & & & $1,131(5 \mathrm{c}$ & 7\%) & 403 & $.9 \%)$ & & $1.03(0 . \varepsilon$ & $-1.25)$ & 0.8 \\
\hline Other/los & to follo & & & $186(9$. & & 82 & $.7 \%)$ & & $0.83(0.6$ & $-1.12)$ & 0.2 \\
\hline Cases & Age & Sex & $\begin{array}{l}\text { FIT } \\
\text { (ng/mg } \\
\text { feces) }\end{array}$ & $\begin{array}{l}\text { Colorectal } \\
\text { cancer } \\
\text { stage }\end{array}$ & $\begin{array}{l}\text { Localiza- } \\
\text { tion }\end{array}$ & $\begin{array}{l}\text { Size } \\
(\mathrm{cm})\end{array}$ & $\begin{array}{l}\text { Time from } \\
\text { colonoscopy } \\
\text { (months) }\end{array}$ & $\begin{array}{l}\text { Resec } \\
\text { polyp } \\
\text { same }\end{array}$ & $\begin{array}{l}\text { ction of } \\
\text { ps in the } \\
\text { zone }\end{array}$ & $\begin{array}{l}\text { Quality of } \\
\text { colonoscopy }\end{array}$ & Dead \\
\hline Case 1 & 66 & M & 158 & III & Rectum & 6 & 24 & No & & Poor & No \\
\hline Case 2 & 65 & $\mathrm{~F}$ & 825 & IV & Sigmoid & - & 18 & No & & Good & No \\
\hline Case 3 & 58 & M & 13,042 & IV & Transverse & - & 48 & No & & Good & Yes \\
\hline Case 4 & 64 & M & 1,402 & III & Sigmoid & & 38 & Yes & & Poor & No \\
\hline Case 5 & 59 & $\mathrm{~F}$ & 4,357 & III & Cecum & 5.5 & 33 & No & & Good & Yes \\
\hline Case 6 & 58 & $\mathrm{~F}$ & 13,235 & I & Cecum & 1.5 & 7 & Yes & & Good & No \\
\hline Case 7 & 62 & $\mathrm{~F}$ & 107 & IV & Transverse & - & 14 & No & & Good & No \\
\hline Case 8 & 64 & M & 100 & ॥ & Descending & 4 & 46 & Yes & & Good & No \\
\hline Case 9 & 61 & M & 1,194 & IV & Cecum & 7 & 23 & No & & Good & Yes \\
\hline Case 10 & 68 & M & 396 & III & Rectum & 6 & 21 & No & & Good & No \\
\hline Case 11 & 58 & M & 188 & I & Sigmoid & 2.5 & 22 & No & & Good & No \\
\hline Case 12 & 60 & $\mathrm{~F}$ & 953 & ॥ & sigmoid & 4 & 21 & No & & Good & No \\
\hline Case 13 & 63 & M & 119 & III & Sigmoid & 3 & 42 & No & & Poor & No \\
\hline
\end{tabular}

A total of 19,942 (40.9\%) cases of AA and 2,607 (5.3\%) of CRC were detected, representing a total of 22,549 (46.2\%) cases of AN, while 8,670 (17.8\%) patients had low risk adenomas. The ADR was $64 \%$ overall, the rate being significantly higher in non-academic than academic hospitals $(66.4 \%$ vs $63.1 \% P<0.001)$. Rates of AN detected per screening round were $50 \%, 40 \%$ and $40 \%$ in the first, second and third round, respectively. The rate of AN detection was lower in academic hospitals (45.3\% vs 48.7\%; OR 0.87, 95\% Cl 0.84-0.91; $P<$ $0.001)$. Regarding stage of diagnosis, $70 \%$ of CRCs detected were at an early stage (I-II) at time of diagnosis. Overall, $57 \%$ of T1 cancers were treated by endoscopy alone. No significant differences were found by hospital type, either in diagnosis of early-stage CRC or in number of patients with CRC treated by endoscopy ( $>$ Table 2). CRC was diagnosed after colonoscopy in 13 patients in the academic hospital group ( 0.26 cases $x$ 1000 colonoscopies); in contrast, there were no cases of postcolonoscopy CRC in non-academic hospitals. Table 3 describes characteristics of patients with interval cancer after colonoscopy.

The total complication rate was $1.2 \%$ (602 patients), with no significant differences by hospital type or age group. Hemor- 
- Table 4 Complications by hospital type.

\begin{tabular}{|l|c|c|c|}
\hline & $\begin{array}{l}\text { Academic hospitals } \\
\text { no. of colonoscopies; } 34,616\end{array}$ & \multicolumn{2}{|c|}{$\begin{array}{l}\text { Non-academic hospitals } \\
\text { no. of colonoscopies; 14,143 }\end{array}$} \\
\hline Total & $431(1.2 \%)$ & $171(1.2 \%)$ & 0.4 \\
\hline Serious & $389(1.1 \%)$ & $150(1 \%)$ & 0.2 \\
\hline - Hemorrhage & $245(63.1 \%)$ & $85(55.5 \%)$ & $<0.05$ \\
\hline - Perforation & $103(26.8 \%)$ & $45(29.4 \%)$ & 0.3 \\
\hline - Sedation & $8(1.9 \%)$ & $2(1.2 \%)$ & 0.4 \\
\hline - Other & $32(7.4 \%)$ & - & 0.3 \\
\hline - Death & $1(0.2 \%)$ & $18(10.5 \%)$ & 0.4 \\
\hline Non-serious & & $2(1.2 \%)$ & 0.4 \\
\hline - Sedation & $33(7.7 \%)$ & & 0.2 \\
\hline - Other & $9(2.1 \%)$ & & \\
\hline
\end{tabular}

rhage was the most common type of complication, occurring in $1 / 147$ colonoscopies, and was more frequent in academic hospitals ( $\triangleright$ Table 4 ). Men had a higher risk of bleeding than women, with an OR of $1.86(95 \% \mathrm{Cl}, 1.31-2.65 ; P=0.001)$. Bleeding was also associated with polyp size $\geq 2 \mathrm{~cm}$ and a larger number of polyps. Perforation occurred in $1 / 329$ cases, and again, men were at higher risk than women $(\mathrm{OR}, 1.58 ; 95 \% \mathrm{Cl}, 1.06-2.33$; $P=0.022$ ). Perforation was also associated with colonic diverticula, poor preparation, removal of large polyps $(\geq 2 \mathrm{~cm})$ and previous abdominal surgery. Lastly, the rate of other complications requiring hospitalization such as post-polypectomy syndrome or those related to sedation was 1/799 colonoscopies, with a significantly higher risk in women than men (OR, 2.21; $95 \% \mathrm{Cl}, 1.30-3.77 ; P=0.003)$. One death was recorded within 30 days after screening colonoscopy due to peritonitis following perforation.

\section{Discussion}

In our study, in screening colonoscopies after fecal occult blood testing, we observed a higher ADR when colonoscopy was performed in non-academic hospitals. Specifically, the ADR in our population screening program after a positive FIT was $64 \%$ overall, with rates of $66.4 \%$ in non-academic and $63.1 \%$ in academic hospitals, respectively. ADR is the main quality indicator for colonoscopy and is inversely associated with risks of interval colorectal cancer, advanced-stage interval cancer, fatal interval cancer and mortality $[16,17]$. Further, it is a marker that indirectly reflects other surrogate quality indicators such as quality of bowel preparation, colonoscopy completeness, and withdrawal time.

It has been suggested that ADR after a positive FIT should be greater than $40 \%$ [4]. In the COLONPREV clinical trial comparing FIT with colonoscopy in CRC population screening in middle-aged people, we observed an ADR of $31 \%$ in the colonoscopy group and 55\% (range, $21 \%-83 \%$ ) in the FIT group (17); in that study, individuals with a hemoglobin concentration $\geq 15 \mathrm{mg} \mathrm{Hb} / \mathrm{g}$ feces were invited for colonoscopy. These findings are concordant with studies of other CRC screening programs based on fecal occult blood testing, which have found similar mean ADRs: $44.8 \%$ in the Italian screening program (using FITs) and $46.5 \%$ in the National Health Service Bowel Cancer Screening Program in England (using guaiac-based tests) [9, 18].

Interval CRC after colonoscopy is another fundamental factor to assess quality of colonoscopy with reported rates ranging from 0.3 to 1.7 cases per 1,000 colonoscopies $[11,19,20]$. In our study, we found 0.26 cases per 1000 colonoscopies. There is agreement that there are three main explanations for postcolonoscopy CRC: missed advanced neoplasia, new lesions and incompletely resected lesions. The most important factor related to missed advanced neoplasia is the ADR, which in turn depends on cecal intubation rate, withdrawal time, and colon cleansing [15, 18, $21-27]$. All these factors are interrelated. In general, in these studies, ADR has been seen to correlate with cecal intubation rate and degree of cleansing: the better the cleansing, the higher the ADR; and the higher cecal intubation rate, the higher the ADR.

If physicians with lower ADRs are also less likely to completely resect polyps, the high subsequent risk of cancer among their patients may be due, at least in part, to incomplete resection rather than decreased detection alone [16]. Notably, in onequarter of cases of interval CRC in our study, cancer developed in a colonic segment where a polypectomy had been performed during the prior colonoscopy. We underline that to decrease post-colonoscopy CRC, there is a need, in particular, for measures to: enhance visualization, particularly on proximal folds; increase cecal intubation rates; improve visualization of polyp resection margins; and improve detection of serrated pathway lesions, together with refined surveillance intervals and better training and quality assurance [4].

Our findings could be explained at least partially by trainee physicians having performed colonoscopies without adequate supervision or longer withdrawal times at non-academic hospi- 
tals. Unfortunately, withdrawal time is a parameter about which data were not collected systematically in our screening program. Another factor that might explain our findings would be a higher level of motivation among staff (doctors and nurses) in non-academic hospitals in relation to screening colonoscopies and in preparation of intestinal cleansing. Further research is needed to clarify the factors underlying the differences observed. We believe that trainees should not be included in the screening program; rather only the best performing should carry out screening colonoscopies.

Serious complications of colonoscopy include death, perforation, and bleeding, which is the most frequent. The reported rate of postpolypectomy bleeding ranges from 0.07 to $1.7 \%$ (28), and consistent with this, hemorrhage occurred in $1.1 \%$ of patients in our study. Previous studies have identified various factors associated with postpolypectomy bleeding, including polyp size, location in the right colon, sessile morphology, number of polyps, comorbidities, experience of the endoscopist, number of polyps removed, and use of antiplatelet and anticoagulant drugs [28].

Rates of CRCs in early stages and treatment by endoscopy were similar in both types of hospitals. In general, CRC polyps are relatively large and difficult to excise. In our program, aspirin at low doses was not withdrawn, while patients on any antiplatelet drugs were switched to aspirin at low doses and anticoagulants were withdrawn. European Society of Gastrointestinal Endoscopy guidelines state that polyps can be safely removed without interruption of aspirin therapy, but there is ongoing debate about polyp removal without interruption of thienopyridines (ticlopidine, clopidogrel, prasugrel, and ticagrelor) and anticoagulants because of the paucity of data available on the safety of the procedure [29]. American College of Chest Physicians guidelines recommend therapy with low-molecularweight heparin if oral anticoagulants are suspended, depending on thrombotic risk [30].

In our study, the rate of treatment of patients with CRC by endoscopy was very high (30\%, 785 cases), higher than that reported elsewhere in Europe (23\%) [31]. More than two-thirds of CRCs (70\%) were classified as early-stage disease ( $\mathrm{N}$ negative), this rate being similar in both types of hospital and similar to that in other screening programmes using FITs. There were no differences in endoscopic treatment by hospital type. The rate of perforation was 1/329 colonoscopies and was associated with colonic diverticular, poor preparation, removal of large polyps ( $\geq 2 \mathrm{~cm}$ ) and previous abdominal surgery. In a 2009 review, rates of perforation were found to be 1/1,400 overall and $1 / 1,000$ for therapeutic colonoscopies [32]. An explanation for the differences may be that studies are generally conducted in referral hospitals or based on datasets in which frequencies may be underestimated. Advanced age, female sex, presence of multiple comorbidities, diverticulosis, and bowel obstruction have previously been shown to increase risk of perforation [33]. Varying perforation rates have been estimated for polypectomies, endoscopic mucosal resections, and endoscopic submucosal dissections.

Non-academic hospitals had the highest rate of ADR and therefore a higher rate of polypectomies. This increases risk of bleeding and explains differences in rates of this complication between hospital types. Nevertheless, no differences were found in risk of colon perforation by hospital type, probably because the risk of this type of complication is much lower.

The limitations of our study include that it was not prospective, the aim was not to determine risk of complications, and withdrawal time was not recorded. On the other hand, its strengths include the population-based approach without selection of hospitals or endoscopists, which means that the data reflect routine clinical practice. Further, the percentage of colonoscopies that were not analyzed due to patients going to private hospitals was low (6.6\%). Finally, a registry database was developed and initiated in a systemic structured manner, using internationally accepted standards to report medical descriptions and diagnoses, and this facilitates uniform identification of CRC cases.

\section{Conclusion}

In conclusion, we believe that screening colonoscopies can be performed in non-academic hospitals with similar results to those obtained in academic hospitals.

\section{Supplementary note Investigators of EUSKOLON study}

Jose Luis Hurtado (Primary Care Unit, Araba Integrated Health Organization [IHO]); Carmen de No (Biochemistry Unit, Araba University Hospital [AUH]); Carlos Enciso, Maite Escalante, Luis Francisco Eraña (Gastroenterology Unit, AUH); Begoña Atarés, Jose Javier Aguirre, Esther Pereda (Pathology Unit, AUH), Edurne Marañón (Primary Care Unit, Alto Deba IHO); Pedro Otazua, Maria Fernández (Gastroenterology Unit, Alto Deba Hospital); Jose Francisco Egido (Primary Care Unit, Bajo Deba IHO); Eva Zapata, Leire Zubiaurre (Gastroenterology Unit, Mendaro Hospital); Juana Mari Rodriguez (Pathology Unit, Mendaro Hospital); Pedro Esteban Sampedro (Primary Care Unit, Bidasoa IHO); Marisa Goyeneche (Gastroenterology Unit, Bidasoa Hospital); Jose Maria Arrinda (Pathology Unit, Bidasoa Hospital); Mari Carmen Milagros Gómez (Primary Care Unit, Tolosaldea IHO); Management Mari Luz Jauregui (Tolosaldea IHO Management); Marta Gómez (Gastroenterology Unit, Zumarraga Hospital); Marta Sáiz (Pathology Unit, Zumarraga Hospital); Rafael Rotaeche, María A. Gutierrez-Stampa, Vanessa Aguilar-Gama (Primary Care Unit, Donostialdea IHO); Luis Bujanda, Inés Gil, Jesus Banales, María J. Perugorria, Mauro D’Amato, Cristina Sarasqueta (Gastroenterology Unit, Donostia University Hospital [DUH]); Isabel Montalvo (Gastroenterology, Unit Onkologiko Hospital); Jose Miguel Larzabal, Maddi Garmendia (Pathology Unit, DUH); Fernando Izquierdo (Biochemistry Unit, Galdakao Hospital); Francisco Javier Fernández, lago Rodriguez, Alain Huerta (Gastroenterology Unit, Galdakao Hospital); Eduardo de Miguel, Inmaculada Barredo (Pathology Unit, Galdakao Hospital); Fidencio Bao, Anaiansi Hernández (Gastroenterology Unit, San Eloy Hospital); Isabel Rodriguez, Josebe Fernández (Primary Care Unit, Bilbao-Basurto IHO); Maria Imaz (Biochemistry Unit, Basurto University Hospital [BUH]); Angel Calderón, 
Francisco Polo (Gastroenterology Unit, BUH); Nagore Arbide, Carmen Etxezarraga (Pathology Unit, BUH); Gaspar Lantarón, Cristina Quesada, Cristian Amezaga (Primary Care Unit, Ezkerraldea-Enkarterri-Cruces IHO); Itziar Marzana (Biochemistry Unit, Cruces University Hospital [CHU]); Enrique Ojembarrena, Haritz Cortés, Iñaki Casado (Gastroenterology Unit, CUH); Mar Ramirez, Amaia Aperribay, José Ignacio López (Pathology Unit, CUH); Lorea Martínez-Indart, Marta Estalella; José Ignacio Pijoan (BioCruces Health Research Institute); Marta de la Cruz, Joseba Bidaurrazaga, Nerea Muniozguren (Bizkaia Tomour Registry); Nerea Larrañaga (Gipuzkoa Public Health Department); Covadonga Audicana (Department of Health, Basque Country); Isabel Bilbao (Colorectal Cancer Screening Programme, Basque Health Service); Jose Luis Bilbao, Eduardo Millan (Basque Health Service); Saloa Unanue (University of the Basque Country); Nere Mendizabal (Primary Care Research Unit of Bizkaia), Iñaki Gutiérrez-Ibarlucea.

\section{Competing interests}

\section{None}

\section{References}

[1] Departamento de Sanidad y Consumo. Cancer in the Basque Country. Incidence, mortality, survival and their trends Gasteiz: 2010; 1st: edn. http://www.osakidetza.euskadi.eus/contenidos/informacion/ estado_salud/es_5463/adjuntos/cancer_en.pdf

[2] GLOBOCAN. Estimated cancer incidence, mortality and prevalence worldwide in 2012.http://globocan.iarc.fr/Default.aspx [Available: 2016-08-19]

[3] Kaminski MF, Regula J, Kraszewska E et al. Quality indicators for colonoscopy and the risk of interval cancer. N Engl J Med 2010; 362: $1795-1803$

[4] Jover R, Herráiz M, Alarcón O et al. Clinical practice guidelines: quality of colonoscopy in colorectal cancer screening. Endoscopy 2012; 44: $444-451$

[5] Arana-Arri E, Idigoras I, Uranga B et al. EUSKOLON Group. Populationbased colorectal cancer screening programmes using a faecal immunochemical test: should faecal haemoglobin cut-offs differ by age and sex? BMC Cancer 2017; 17: 577

[6] Idigoras I, Arrospide A, Portillo I et al. Evaluation of the colorectal cancer screening Programme in the Basque Country (Spain) and its effectiveness based on the Miscan-colon model. BMC Public Health 2017; 18: 78

[7] Von Karsa L, Patnick J, Segnan N et al. European guidelines for quality assurance in colorectal cancer screening and diagnosis: Overview and introduction to the full Supplement publication. Endoscopy 2013; 45: $51-59$

[8] Red de Programas de Cribado de Cáncer. Situación de los Programas de Cribado de Cáncer Colorectal en España 2012: [Available: 201608-19] http://www.programascancerdemama.org

[9] Hassan C, Quintero E, Dumonceau JM et al. Post-polypectomy colonoscopy surveillance: European Society of Gastrointestinal Endoscopy (ESGE) Guideline. Endoscopy 2013; 45: 842-851

[10] Edge SB, Byrd DR, Compton CC et al. (Ed) AJCC Cancer Staging Manual. 7th ed. New York: Springer; 2010
[11] Adler J, Robertson D]. Interval colorectal cancer after colonoscopy: exploring explanations and solutions. Am J Gastroenterol 2015; 110 : $1657-1664$

[12] Bjerrum A, Milter MC, Andersen O. Risk stratification and detection of new colorectal neoplasms after colorectal cancer screening with faecal occult blood test: experiences from a Danish screening cohort. Eur J Gastroenterol Hepatol 2015; 27: 1433 - 1437

[13] Portillo I, Arana-Arri E, Idigoras I et al. Colorectal and interval cancers of the Colorectal Cancer Screening Program in the Basque Country (Spain). World J Gastroenterol 2017; 23: 2731 - 2742

[14] Lai E], Calderwood AH, Doros G et al. The Boston bowel preparation scale: a valid and reliable instrument for colonoscopy-oriented research. Gastrointest Endosc 2009; 69: 620-625

[15] Calderwood AH, Jacobson BC. Comprehensive validation of the Boston Bowel Preparation Scale. Gastrointest Endosc 2010; 72: 686-692

[16] Corley DA, Jensen CD, Marks AR et al. Adenoma detection rate and risk of colorectal cancer and death. N Engl J Med 2014; 370: 1298 1306

[17] Cubiella J, Castells A, Andreu M et al. Correlation between adenoma detection rate in colonoscopy- and fecal immunochemical testingbased colorectal cancer screening programs. United European Gastroenterol J 2017; 5: 255-260

[18] Zorzi M, Fedeli U, Schievano E et al. Impact on colorectal cancer mortality of screening programmes based on the faecal immunochemical test. Gut 2015; 64: 784-790

[19] Pohl H, Robertson DJ. Colorectal cancers detected after colonoscopy frequently result from missed lesions. Clin Gastroenterol Hepatol 2010; 8: 858-864

[20] Kahi C], Imperiale TF, Juliar BE et al. Effect of screening colonoscopy on colorectal cancer incidence and mortality. Clin Gastroenterol Hepatol 2009; 7: 770-775

[21] Baxter NN, Sutradhar R, Forbes SS et al. Analysis of administrative data finds endoscopist quality measures associated with postcolonoscopy colorectal cancer. Gastroenterology 2011; 140: 65-72

[22] Hoff G, Holme $\varnothing$, Bretthauer M et al. Cecum intubation rate as quality indicator in clinical versus screening colonoscopy. Endosc Int Open 2017; 5: E489-E495

[23] Gupta M, Holub JL, Eisen G. Do indication and demographics for colonoscopy affect completion? A large national database evaluation Eur ] Gastroenterol Hepatol 2010; 22: 620-627

[24] Bhangu A, Bowley DM, Horner R et al. Volume and accreditation, but not specialty, affect quality standards in colonoscopy. Br J Surg 2012; 99: $1436-1444$

[25] Gimeno-García AZ, Baute JL, Hernandez G et al. Risk factors for inadequate bowel preparation: a validated predictive score. Endoscopy 2017; 49: 536- 543

[26] Dik VK, Moons LM, Hüyük M et al. Colonoscopy Quality Initiative. Predicting inadequate bowel preparation for colonoscopy in participants receiving split-dose bowel preparation: development and validation of a prediction score. Gastrointest Endosc 2015; 81: 665-672

[27] Manes G, Repici A, Hassan C. MAGIC-P study group. Randomized controlled trial comparing efficacy and acceptability of split- and standard-dose sodium picosulfate plus magnesium citrate for bowel cleansing prior to colonoscopy. Endoscopy 2014; 46: 662-669

[28] Pigò F, Bertani H, Manno M et al. Colonic Postpolypectomy Bleeding Is Related to Polyp Size and Heparin Use. Clin Endosc 2017; 50: 287 292

[29] Veitch AM, Vanbiervliet G, Gershlick AH et al. Endoscopy in patients on antiplatelet or anticoagulant therapy, including direct oral anticoagulants: British society of gastroenterology (BSG) and European society of gastrointestinal endoscopy (ESGE) guidelines. Endoscopy 2016; 48: 385-402 
[30] Douketis JD, Spyropoulos AC, Spencer FA et al. Perioperative management of antithrombotic therapy: antithrombotic therapy and prevention of thrombosis, 9th ed: American college of chest physicians evidence-based clinical practice guidelines. Chest 2012; 141: (Suppl. 02): e326S-e350S

[31] Tepeš B, Bracko M, Novak Mlakar D et al. Results of the FIT-based National Colorectal Cancer Screening Program in Slovenia. J Clin Gastroenterol 2017; 51: e52-e59
[32] Panteris V, Haringsma J, Kuipers E]. Colonoscopy perforation rate, mechanisms and outcome: from diagnostic to therapeutic colonoscopy. Endoscopy 2009; 41: 941 - 951

[33] Arora G, Mannalithara A, Singh G et al. Risk of perforation from a colonoscopy in adults: a large population-based study. Gastrointest Endosc 2009; 69: 654-664 